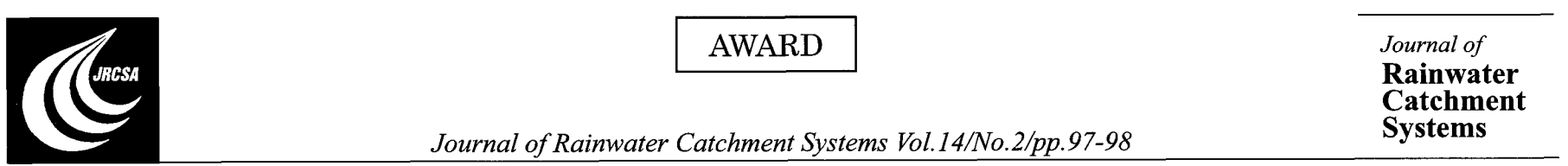

\title{
Numerical Modelling of Flow in Fishways Using Shallow Water Equations
}

\author{
Masayuki Fujihara ${ }^{1}$
}

It is highly esteeming and a great honor to have received a nomination for the 2008 JRCSA Award and being presented with it during the 16th JRCSA annual congress held on November 1, 2008 in Tsuruoka, Yamagata, which was organized by Dr. Yuki Nakajima, Executive and Vice-President of Yamagata University. I extend my sincere thanks to the Award Screening Committee, chaired by Dr. Yoshitaka Yoshitake, Professor of Ehime University, for elevating me to the status of a JRCSA Award recipient; and to the members of the JRCSA Executive Board and Council headed by Prof. Dr. Tsugio Ezaki, President of JRCSA. Also, special thanks are due to Dr. Tadao Fukushima, Professor Emeritus of Ehime University, and other co-workers for pursuing projects with me.

\section{Numerical Shallow Water Equation Using Godu- nov-type Riemann Solver and Quadtree Grids}

For the last 10 years, I have been involved in a shallow water numerical simulation. When I was an academic visitor of the University of Oxford from June 1998 to May 1999, I started to investigate the numerical modelling of shallow water equation, co-operating with Dr. Alistair Borthwich, Professor of the University of Oxford. In discretization of the shallow water equation, unless the discretization of convective term is precisely treated, we fail to obtain a proper result. Then, we employed a Godunov-type Riemann solver for inviscid flux terms. Roe's scheme (Roe, 1981), which is one of the approximate Riemann solvers, was used in our series of works. It is applicable to both the subcritical and supercritical flows and can also clearly capture a discontinuous front, such as a hydraulic jump or a dam-break flow.

On the other hand, considering the complicated natural shallow water regions, it is also important for numerical models to generate computational grids fitting into the flow boundaries correctly. Structured grids based on boundary-fitted curvilinear systems have been widely used for the models of natural rivers and coastal areas to reproduce land boundaries correctly. For flow-fields with multiple bodies, however, it is particularly difficult to generate structured grids. In the past several years, unstructured grid methods, which are commonly used in finite element methods, have become more and more prevalent even in finite difference methods. Generally, grid generators ideally

\footnotetext{
${ }^{1}$ Professor, Faculty of Agriculture, Ehime University, 3-5-7 Tarumi, Matsuyama, Ehime 790-8566, Japan. E-mail: fujihara@agr.ehime-u.ac.jp
}

should be automatic and robust, and should fit the flow boundaries correctly. Hierarchical grid generation appears to be an attractive option in that it meets most of the foregoing requirements. Quadtree grids used in our works is one of hierarchical grids. Quadtree grids offer a high resolution and locally-refined mesh consisting of quadrilateral cells. Quadtree grids are generated by recursive subdivision of cells to a level determined by a prescribed subdivision criterion. This technique was originally used for spatial decomposition of digitised images. The method has since been used in the flow simulation as an efficient use of computer storage and for data handling. Two-dimensional quadtree grids (Rogers et al., 1998) may be produced extremely quickly by simple spatial decomposition into squares.

The computational model presented consists of a grid generation based on quadtree grids, and a flow solver based on the MUSCL (Monotonic Upstream-Centred Scheme for Conservation Laws) concept with slope limiter and Roe's approximate Riemann solver. The shallow water equations are discretized using finite volumes collocated with the grid cells, and integrated in time using a 4th order Runge-Kutta scheme. The accuracy of the model was demonstrated through a hydraulic jump on a horizontal bottom and tidal wave propagation into a channel with non-uniform bathymetry. (Fujihara, 2000)

\section{Application to Flows in Fishways}

As the concern for conservation or improvement of natural rivers for fish habitats has been widespread, fishways are becoming attractive to the major interests of river engineers and fluvial ecologists, as well as for inland fishermen. Fishways are hydraulic structures that enable fish to go through obstructions to their spawning and other migration areas. Most of the earlier studies of fishways have focused on the flow structure by means of hydraulic models and field observations. Field observations have been conducted to verify whether fish pass through the fishways installed and to investigate when fish pass through them from the ecological point of view.

Since most of the flow structures in fishways are complicated with free surface and sub- and super-critical flow conditions usually coexist, numerical models of fishways have not been established yet. This is the reason why the earlier studies have resorted to model experiments and field observations. If a numerical model which is applicable to the flow in fishways is available, it could be a convenient and economical tool in designing fishways. 


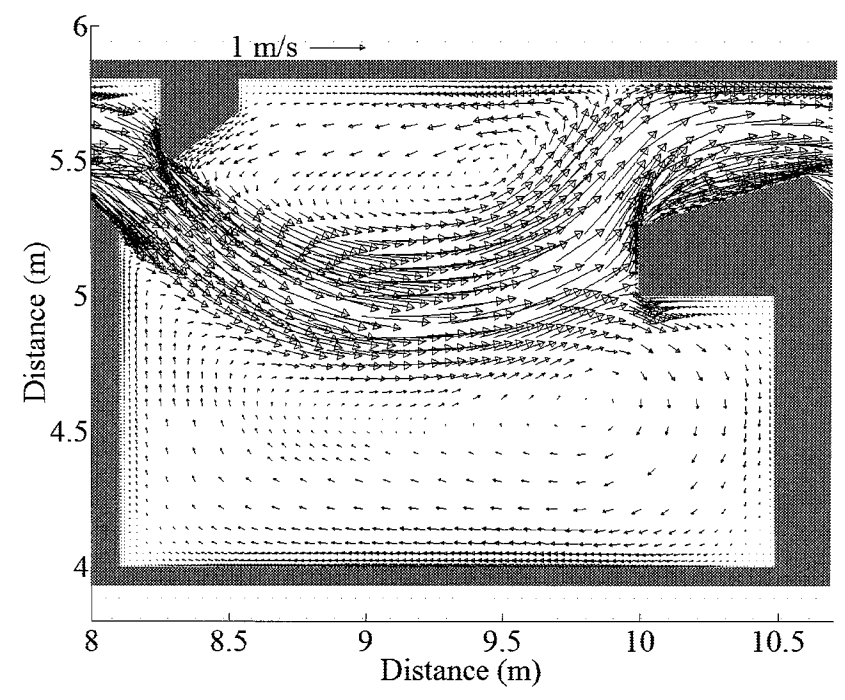

Figure 1: Velocity vector in the vertical slot fishway using solutio-adaptive grids

Then the above mentioned model was applied to the flows in several types of vertical slot fishway and nature-like fishways embedded with stones and validated through theoretical and experimental results.

\subsection{Vertical slot fishway}

Vertical slot fishways are one of the main types of fishways that are generally used for upstream passage of fish in streams. Basically, the vertical slot fishway is a rectangular channel that includes a number of pools partitioned by vertical baffles with a slot. Water runs downstream through a vertical slot from one pool to the next. The water forms a jet as it goes through the slot and the energy is dissipated effectively by jet mixing in the pool.

The above-mentioned model was applied to the flow in three types of vertical slot fishways: center slot type (Fujihara et al., 2001), single- and double-slot types (Fujihara et al., 2003). Moreover the advantage of solution-adaptive quadtree grids was demonstrated through the comparison between the computed results using non-adaptive grids and using adaptive grids (Fujihara and Fukushima, 2002) (see Fig. 1).

\subsection{Nature-like Fishways Embedded with Stones}

Nature-like fishways or rocky ramp fishways, consists of a sloping channel embedded with a set of natural or artificial obstructions. The key factors that an engineering designer should consider when designing such kinds of fishways are shorter fish pathways, deeper water depths to enable big fish to take fishways and larger lower velocity region for fish to take rest. Though these kinds of fishways mimic the flow of natural streams and are considered favorable for large species of fish as well as invertebrates, the widespread construction of such kinds of fishways has been constrained by the lack of concrete design guidelines.

The presented model was applied to the flow over a series of semi-spherical obstructions in a ramp fishway and a proper longitudinal distance between obstructions was

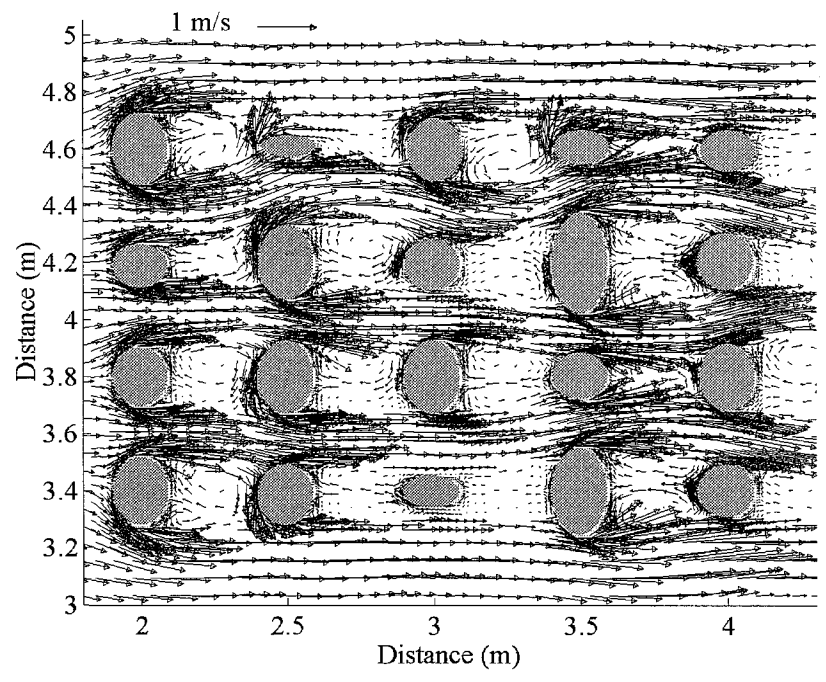

Figure 2: Velocity vector in a nature-like fishway embedded with stones.

demonstrated (Fujihara and Chhatkuli, 2006). Considering natural stones are used as obstructions, gross effect of multiple elliptical obstacles with different aspect ratios was analyzed. The change in flow parameters because of the increment in the standard deviation of shape variation has been numerically compared (Chhatkuli and Fujihara, 2006; Fujihara and Izumi, 2007)(see Fig.2).

\section{References}

[1] Chhakuli, S. and Fujihara, M. (2007): Numerical Experiments of the Effects of Obstructions Shape Variation on the Flow in Nature-like fishways, J. Rainwater Catchment Systems, JRCSA, 13(1), pp.11-16.

[2] Fujihara, M. (2000): Numerical Shallow Water Simulation Using Godunov-Type Scheme on Quadtree Grids, J. Rainwater Catchment Systems, JRCSA, 6(1), pp.13-20.

[3] Fujihara, M., Kinoshita, S., and Fukushima, T. (2001): An Application of Godunov-type Scheme to Flow in a Vertical Slot Fishway, J. Rainwater Catchment Systems, JRCSA, 6(2), pp.21-26.

[4] Fujihara, M. and Fukushima, T. (2002) : An Application of Solutio-adaptive Quadtree Godunov-type Scheme in Finite Volumes to Flow in a Vertical Slot Fishway, Fisheries Engineering, JSFE, 39(2), pp.117-123. (in Japanese).

[5] Fujihara, M., Fukushima, T., and Tachibana, K. (2003): Numerical Investigations of Flow in Vertical Single- and Double-slot Fishways, Trans. Irrig., Drain, and Recla. Engng., JSIDRE, 223, pp.79-88.

[6] Fujihara, M. and Chhatkuli, S. (2006): Numerical Flow Modeling over Semi-Spherical Obstructions in a Series Toward a Numerical Modeling of Nature-like Fishways Embedded with Stones -, Trans. JSIDRE, JSIDRE, 246, pp.151-159.

[7] Fujihara, M. and Izumi M. (2007): Least Considerations for Fish in Agricultural Water Use Systems, J. Jap. Soc. Water Env., JSWE, 30(10), pp.561-565. (in Japanese)

[8] Roe, P. L. (1981): Approximate Riemann Solvers, Parameter Vectors, and Difference Schemes, J. Comp. Phys., 43, pp.357-372.

[9] Rogers, B., Fujihara, M., and Borthwick. A. G. L. (2001): Adaptive Q-tree Godunov-type scheme for shallow water equations, Int. J. Numer. Meth. Fluids, 35, pp.247-280. 